\title{
From implementation to appropriation: Understanding knowledge management system development and introduction as a process of translation
}

\author{
Andreas Diedrich \\ Gothenburg Research Institute \\ University of Gothenburg, Sweden
}

Gustavo Guzman

Griffith University, Australia

\section{Citation:}

Diedrich, A. and Guzman, G. (2015) From implementation to appropriation: Understanding knowledge management system development and introduction as a process of translation, Journal of Knowledge Management, 19(6): 1273-1294. 


\title{
From implementation to appropriation: Understanding knowledge management system development and introduction as a process of translation
}

\begin{abstract}
Purpose. This paper examines the complexities emerging in the attempts to develop a sophisticated IT-based Knowledge Management system for sharing knowledge. Using actornetwork theory, the authors conceptualise this as continuous processes of translation, whereby heterogeneous human and non-human (e.g. technologies, methods, plans) elements are drawn together and mobilised to produce stable networks through associations between them.
\end{abstract}

Design/methodology/approach. The case study method was adopted using a narrative approach that studies the ways of organising work in organisations. Shadowing, field notes, diary studies and participant observation were the main data collection methods used.

Findings. The development and introduction of a KM system is a contingent and local process shaped by messy translations whereby the original idea, human and other non-human elements are reconfigured. By considering humans and non-humans symmetrically, the intended and unintended actions, and the role of unexpected events, this approach overcomes the deterministic view of human nature of the conventional KMS approaches.

Research implications. A conceptual framework is presented as a means to improve the understanding of the complex associations emerging within networks of people, objects and machines during the development and introduction of KMS. 
Practical implications. The translation approach helps practitioners to consider their takenfor-granted assumptions about people, machines and the associations among them. This assists practitioners to uncover emerging conflicting issues between human and machines, among machines, and among humans. Furthermore, this allows practitioners to recognise the different identities humans and non-humans take, overtime, as a result of emerging associations.

Originality/value. The originality of this paper lies in the use of alternative conceptual lenses (ANT) to understand KMS development and introduction as processes of translation. Additionally, rather than exploring the success stories, it focuses on a failed attempt to introduce a KMS.

Key Words: knowledge management systems, development, translation, actor-network theory.

\section{Introduction}

The goal of this paper is to examine the complexities emerging in the attempts to develop a sophisticated IT-based Knowledge Management system (KMS) for sharing knowledge in the form of best practice, using Actor-Network Theory (ANT). The authors use the work of Bruno Latour (1987, 1991, 2005), who views innovation as a process of translation by which a vague initial idea is shaped and transformed through negotiations and mediations, to build up a network of allies who believe in, test, and carry forward the development of the innovation. The authors argue efforts to develop and introduce KMS can be conceptualised as continuous processes of translation, whereby heterogeneous human and non-human elements are drawn together and mobilised to produce stable networks through associations between 
them. Such a translation approach produces more nuanced explanations about the social practices that underpin the development and introduction of KMS, as well as their intended and unintended outcomes.

This approach has recently gained currency in the management and organisation studies as a way to meaningfully capture the complexities of organisational change (e.g. Czarniawska and Hernes, 2005; Czarniawska, 2009). This is relevant because the translation approach helps to overcome some of the weaknesses of the conventional literature about the development and introduction of KM systems, contributing to a strengthening of both theory and practice.

Existing accounts of KMS development and 'implementation' can be classified roughly into two groups. The first group of studies focussed on formal systematic or 'hard' aspects of the development and implementation of KMS. These include: the adaptation of business processes (Maier and Remus, 2002; Akhavan et al., 2006); the stages of implementation (Szulanski, 2000; Wong, 2005); knowledge architectures (Sua, Hwang and Liue, 2000); and, business processes to be reengineered (Akhavan et al., 2006). The second group of studies, recognising the tacit nature of knowledge (Styhre, 2003; du Plessis, 2007), focussed on the situated, serendipitous or 'soft' aspects, such as culture (Zheng, Yang and McLean, 2010); training (Carneiro, 2000); trust (Politis, 2003); and communities of practice (Iverson and McPhee, 2002; Su et al. 2012).

Likewise, Dufour and Steane (2007) have grouped the KM implementation literature into four approaches: the classical approach, the contingency view, the behavioural approach, and the political approach. Firstly, the classical approach assumes a unitarist view of organisations where consensus and rational actions prevail. It focuses on the development of the sequential implementation phases and IT-based tools, structured along rational arguments 
of efficiency and productivity. Secondly, the contingency view is an open approach that considers the role of the environment. It is deterministic, since engineering circumstances, and contextual factors or the types of knowledge employed are perceived as defining the results of the KM implementation process. Thirdly, the behavioural approach focuses on the individuals' motivation, commitment, and interpersonal cooperation aspects. However, studies employing such an approach usually overlook the context, and the processual, historical and political dimensions of the implementation process. Finally, the political approach looks at how power relations affect, and are affected by, the implementation process. It acknowledges plural independent individuals, resistance, legitimacy, and interest groups within organisational life, aspects ignored by other approaches (Dufour and Steane, 2007: 71-5).

While it is reasonable to think that all these aspects simultaneously emerge and interplay during the development and introduction of KMS, most of the KM literature emphasises one perspective at the expense of other perspectives. Further, the majority of KMS studies are based on functionalist theories that focus on identifying critical success factors and isolating quantifiable variables that are assumed to determine outcomes; they overlook processual approaches that consider context and social relations in the construction of new solutions to situated problems (Gallupe, 2001; Matayong and Mahmood, 2013).

This paper seeks to overcome some of the limitations of the KMS literature by empirically investigating the micro-level dynamics involved in constructing and introducing an IT-based KMS for sharing knowledge. More specifically, this study examines the (unsuccessful) efforts undertaken at a large Scandinavian manufacturing company to share engineering practices between the factories and the divisions, using a KMS that became known as the Best Practice Tool (BPT).The authors examine the actors and their associations, interactions, 
strategies, and tactics. Seeing the conceptualisation of a KMS in this light, ANT allows technical, organizational, and social aspects to be studied together; it also highlights their reciprocal influence in shaping a sustainable KMS or not (as in our case).

It is noteworthy that, while the case reported in this paper is over 10 years old, the elapsed time is not relevant as it focused on how the socio-material efforts, undertaken to develop and introduce a KMS, shaped the outcomes of this project, which ultimately failed. In other words, the authors do not wish to assess whether the system, developed at Engico [2], is the correct solution, nor to decide, as a general rule, what type of latest practical solutions, for the development and introduction of KMS, are superior to others. This decision is determined by the organizational actors in the context of the project itself. Further, the authors think that there is much to learn from historic cases as historians of science and technology have demonstrated (e.g. Bijker, Hughes and Pinch, 1990). By focussing on historic innovations, sometimes dating back 50 to 100 years, researchers were able to trace back, in time, the processes of translation and transformation whereby technological innovations were put together, paving the groundwork for the field of Science and Technology Studies, and ANT in particular.

The remainder of this paper is organised as follows: in the next section the authors discuss ANT as a meaningful approach to explore the complexities of KMS development and introduction; then the authors present the research setting and methodological considerations; after that, the authors explain how KMS development and introduction is a process of translation constituted by continuous negotiations, mediations, and transformations of the initial idea; subsequently the authors propose the idea of KMS appropriation in the discussion section. Finally, in the conclusion section the authors delve into the implications for practitioners, and propose directions for further research. 


\section{KMS, Actor-Network Theory and Translations}

Existing KMS approaches implicitly adopt a particular view of organisations (e.g. technically constrained systems versus socially constructed) and human nature (e.g. voluntaristic versus deterministic), overlooking other aspects. The literature generally has put emphasis on either people, organisational aspects or technology at the expense of the relationships between them [1] (e.g. du Plessis, 2007); planned actions overlooking the role of causality, unexpected events and improvisation (e.g. Lech, 2014); objective and measurable aspects downplaying subjective informal emerging aspects (e.g. Mehta, 2008) and assumes that all actors involved — as if by magic — will act rationally, understand reasons and modify their behaviours accordingly in order to achieve the goals of a project (March et al., 2000).

In this study we attempt to address some of the limitations of previous research on the development and introduction of KM systems. Informed by ANT (Callon, 1986; Latour, 1986, 1987, 1991, 2005), an approach to social theory and research, which includes the role of non-human entities and the way that these resist, allow, deny or assist courses of events, we account simultaneously for the "hard" and "soft" aspects and emerging and continuously transforming relationships involving heterogeneous human and non-human actors, to generate more encompassing explanations about the development and introduction of KM systems, and their success or failure in organisations.

Central to ANT is the concept of translation (Callon, 1986; Latour, 1987) used to explain the processes whereby actor networks are formed through associations between heterogeneous human and non-human elements. As part of these processes, the actors' identities and interests are under constant negotiation and transformation (Callon and Law, 1982; Callon, 1986), yet these identities may become stabilised in relation to each other. 
As a constructivist approach, ANT avoids essentialist explanations of innovations and sees them instead as a process of translation consisting of still undecided controversies by which a vague initial idea is shaped and transformed through the enrolment of human and non-human elements, eventually forming a network of allies who believe in it and carry the innovation on (Latour, 1987). Although it is called a 'theory', ANT does not explain 'why' a network takes the form that it does (Latour, 2005), but shows how it is constructed. It thus seeks to explain the success or failure of an event, an IT project for example, by understanding the combinations and interactions of elements that make the project successful or make it fail, rather than saying that a particular approach to the project is the only "right" one and all the others are "wrong".

From an ANT perspective there is no social, predetermined "stuff" (Latour, 2005) to be studied: rather, every situation is the result of ongoing associations among actors. Viewed in this light, actors, both human and non-human, form and participate in networks, so it is only by following these actors (Latour, 1987, 1996, 2005) and their associations that social and technical/scientific phenomena can be understood. Thus, from an ANT point of view, one should not, for example, explain away the management of knowledge in a company by appealing to a meta-language of efficiency, functionality or social capital. Rather, one should trace the full range of associations that helped to make up the management of the knowledge. And, an actor is also a network held in place. A teacher, for example, can be seen as a network, as she draws on a variety of curricula, presentation tools, technologies, grading forms, study guides, etc. when teaching.

ANT is sometimes, in our view unjustly, criticised for claiming that humans and non-humans (e.g. technologies, tools, etc.) are essentially the same. It is true in the sense that ANT 
assumes everything to be an actor-network - and this includes humans and non-humans. But, Latour never treated them as being essentially the same. Instead, he argued that in analysis the efforts to enrol and control human and non-human resources should be considered symmetrically - in other words, neither should be privileged over the other at the start of the analysis. Furthermore, all networks are different in terms of the roles they play in organising, their differences in turn being constituted by differing actor networks. These differences come about through processes of translation through which "programs-of-action" are inscribed into the network, through the attachment of resources to it and the delegation of roles, responsibilities and identities to other humans and non-human resources (Latour, 1991).

A central idea and motivation behind ANT is to study the construction of things normally taken for granted. Thus, the best time to study such processes is before they become takenfor-granted. Before a full-fledged KMS is in place and black-boxed it is still possible to explore the plethora of actants, human and non-human, mobilised to ensure that a KMS becomes a taken-for-granted part of the knowledge sharing processes and activities in an organisation. As long as the struggles, mediations and negotiations continue and objects too are not yet black-boxed and silenced by their own successful operations they remain visible and can be explored (Latour, 1999: 183). Once a network is in place, all these efforts at organising a KMS will have disappeared and the procedure's inner workings will be obscured from purview.

Thus, instead of focussing solely on particular humans on one side and systems, models, places or outcomes on the other side, the focus of this study is on the (ultimately unsuccessful) attempts at translating the idea of sharing engineering knowledge between factories and divisions into practice as an IT-based KMS for sharing knowledge across 
organisational boundaries through the complex interactions between humans and nonhumans, such as software, computers, IT-infrastructures, servers, etc.

Within this framework, we approach knowledge as socially constructed. That is, rather than seeing knowledge as an object that can be stored, transferred and easily applied using normative and universal methods (c.f. Davenport and Prusak, 1998; O’Dell and Grayson, 1998), it is seen as having both tacit and explicit dimensions and as being situated (contextdependent), socially constructed (enacted by people), embedded in practice and therefore continuously negotiated and (re)produced (Latour and Woolgar, 1979; Orlikowski, 2002; Tsoukas, 2011). Furthermore,, knowledge management is approached, not as a set of welldefined tasks (knowledge acquisition, storage, transfer and creation) (Davenport and Prusak, 1998), but as a set of continuous practices (of decision-making, acting, reflecting, negotiating) performed enacted and/or mediated by heterogeneous elements (human and nonhuman) in order to support the circulation/translation of knowledge (Diedrich, 2004). In other words, the translation of knowledge is here seen as part of larger translation processes that consider both the linguistic and material basis of culture/context. In this way, our perspective also differs from the "knowledge translation" literature, which generally explores the translation of knowledge, in health care settings for example, as a purely linguistic process only (e.g. Graham et al. 2006).

This means that best practices, are socially constructed organisational templates. Because they are situated, tacit, collective and emergent, multiple interpretations are likely to occur, introducing ambiguity about its adaptation to the local context of operation (March et al., 2000; Tsoukas and Vladimirou, 2001; Diedrich, 2004).

\section{The setting}


Engico is one of the leading global manufacturers of products and components for, among others, the electrical and heavy machinery industries. The company employs over 30000 people in 50 countries, and is the world leader in a number of product segments. At the time of study, the company was organised into six divisions, each serving a global market and focusing on its own specific customer segments and an equal number of staff departments. A management team that coordinated the manufacturing and product development process activities of the different factories headed each division. Some of the managers worked at the different production sites; others were stationed at Engico's headquarters. The company's strong engineering culture was especially tangible in one of its staff departments, Corporate Technical Development (CTD), which, apart from coordinating Engico's R\&D and technology innovation activities, was also responsible for the development and introduction of the BPT process.

The engineers at the CTD worked with R\&D activities focusing on both, the development and further improvement of the manufacturing processes and the products manufactured in the factories. At that time, a number of KM procedures and models had been developed at Engico in order to, in the words of the senior managers, counteract the "not-invented-here-syndrome" and keep the divisions from "reinventing of the wheel". For the managers, these "ailments" resulted in much effort and money being wasted in one part of the organisation on solutions that had already developed been developed elsewhere. These remedies included knowledge mapping, e-learning, knowledge repositories and best practice - all aimed at achieving efficiency and increasing productivity through the optimisation of the knowledge resources of the company. The BPT project formed part of these efforts. 


\section{The methods}

In order to account for the main practices that explains the development of the BPT project it was necessary to apply a methodological strategy that considers the fragmented dynamic and multiple contexts in which modern organising evolves. Barbara Czarniawska (1997) suggested an ergonographic approach - a narrative approach that studies ways of organising work in organisations. Accordingly we combined four techniques - shadowing, field notes, diary studies and observant participation (Czarniawska, 2014) - that allowed for a more encompassing observation of complex technologies, a variety of tools, methods and models, a large number of people, decisions, opinions and interests, surprises, controversies and contests, which had messy interconnections (for further details see Diedrich, 2004).

The empirical material for this study was collected by one of the authors. During a 24-month period he gained access to Engico and used a combination of those four data collection techniques. The following persons were interviewed: two Senior Vice Presidents; eight BPT team members; four intended users from the divisions; one previous member of the BPT project; and three persons involved with existing knowledge management activities at Engico. The following meetings were observed three BPT's steering committee meetings; four BPT implementers' meetings; two divisional coordination meetings and four BPT steering committee meetings after the "re-launch" of the system. He was also given the opportunity to access to a large amount of internal documents, such as e-mails, memoranda, information material and product data.

\section{The BPT Project}

The idea of sharing knowledge in the form of best practices with the help of a KMS had recently arrived at Engico in the form of a report compiled by Sweden's Technical Attachés (STATT) - an organisation describing itself as a "global knowledge organisation focusing on 
innovation-related analyses and internationalisation of small and medium-sized companies" (www.statt.se/extern/statt/vision.htm, 2003). Every year, the Attachés would pick a "hot" topic, research it and publish their analyses in a yearly report. The STATT report was the product of a benchmarking exercise and included eight case studies of companies working with knowledge management. These cases were described as "best practice" in KMS. The BPT project started in 2000 and passed through three phases as detailed in Table 1.

\begin{tabular}{|c|c|c|c|}
\hline & Development Phase & Launch Phase & Re-launch Phase \\
\hline Period & Apr 2000 - Nov 2000 & Nov 2000 - Nov 2001 & Nov 2001 - Sep 2003 \\
\hline $\begin{array}{l}\text { Main } \\
\text { activities }\end{array}$ & $\begin{array}{l}\text { Developing the BPT } \\
\text { prototype }\end{array}$ & $\begin{array}{l}\text { Introducing the BPT } \\
\text { system in the } \\
\text { factories and } \\
\text { divisions }\end{array}$ & $\begin{array}{l}\text { Developing new } \\
\text { versions of the BPT } \\
\text { system }\end{array}$ \\
\hline
\end{tabular}

Table 1. The BPT project at glance.

\section{The program of action: "Please share your knowledge across organisational}

\section{boundaries"}

Senior managers at Engico, who were able to connect the STATT report's content to their own experience picked up the report, and became especially interested in an Intranet-based KMS that Ford had developed to spread best practices in the organisation. Interest in knowledge management had been widespread among senior managers at the organisation, because they saw it as a solution to the problems perceived with knowledge sharing across organisational boundaries.According to one manager:

The problem today is that not a lot of knowledge flows between the divisions...they are very goal-oriented...bottom-line, it's the result that counts. It's obvious that you get good cost reduction and better performance by completing these improvements... and that it's 
quicker...the improvement process...because you don't have to develop it yourself. You can use something that comes from another place. [Erik, E011112:3]

This was corroborated by one of Engico's Senior Vice Presidents:

We have a clearly expressed strategy today that says that we want to share knowledge over divisional boundaries. [...]. We have too little of that at the moment. So, when the divisional managers visit other factories they see things and think: why is this not implemented in the other factory? [...]. There are creative people, who've solved problems in a good and creative way in all the factories. And, to then not spread this method they've developed, is, I believe, plain wrong. [Jens, 030506:3]

Senior manager therefore conceived problems with knowledge sharing at Engico and ideas on how to solve them. These ideas can be seen as what Bruno Latour (1990) described as a "program of action - a path that the managers wish their employees in the factories and divisions to follow. At this point in time, there was really not much more than the managers' statement highlighting the need of more knowledge sharing across organisational boundaries, and the STATT report.

The senior managers were at this stage the only ones expressing the need for knowledge sharing across factories and divisions. The division managers, engineers and workers in the factories used Lotus Notes databases in their daily work and praised this "tried and tested" system's abilities to manage their knowledge and information efficiently. According to one divisional manager: 
[T]here you can find all the information about the project: our memos, benchmarking information, customer demand survey. You can also find improvement tools, activity lists and reports from workshops... and local factories have the opportunity to report on their business. [...]. We have operated this database for three years and we today have 325 documents...212 MB of information in it. [...]. And this database is highly frequented for being a project database. Some of the company's big databases are not as highly frequented as ours. [Hans, 020523:9]

Thus, most employees at Engico were not in agreement with the senior managers that more knowledge needed to be shared across organisational boundaries. The managers thus faced the challenge commonly experienced by initiators of organisational change in general: the claims made in the beginning are not particularly strong and depend not only on how the information is communicated, but also on what the audiences - here the employees - do with it. And, a hundred different employees will follow a hundred different paths after being confronted with a novel program of action such as "please share more knowledge across organisational boundaries".

In order for managers to be able to predict the path they can be seen to have two choices: they can either ensure that everyone will know exactly how to make sense of the novel program of action and that they will know that sharing knowledge in their organisation means that knowledge is created in the local factories, but that this knowledge must be shared with other factories and divisions in the organisation in order to avoid the problem that employees are solving the same issues over and over again in different parts of the company. Or, the managers can attach other elements to this program of action in such a way that employees, 
independent of where they work in the organisation or what they do, all are made to behave in the same manner.

As is often the case in KMS development and introduction, the managers at this stage acted in line with the second strategy. In 2000 they put together a project group consisting of managers, engineers and IT specialists with the task of constructing an IT-based tool for sharing knowledge in the form of best practices over organisational boundaries. The group developed what according to them was a "relatively well functioning" software application ready to be launched in the organisation. This was one piece in the complex processes of factbuilding, of creating a prototype that could provide factual evidence to entice and convince the employees of the idea of sharing knowledge across boundaries.

The envisioned process inscribed in the software displayed a certain inherent logic of how to get from a daily work practice of an engineer in a factory to an "implemented best practice" in another part of the organisation. According to the BPT team one of the key aspects of the BPT process was the identification and establishment of so called "communities", organised around different parts of the manufacturing processes and different fields of knowledge, such as machine design, assembly, resetting or metallurgy. These communities were to be Intranetbased, each had its own homepage, and were envisaged to transcend organisational (divisional) boundaries.. Different roles were allocated within the communities: the Community Head had the overall responsibility for the community and for accepting or rejecting proposed best practices. The Best Practice Coordinators were stationed in the factories and were in charge of identifying and describing (local) best practices and sending them via the BPT to the Community Head. The BPT project leader described the envisaged process in the following way: 
The plan is for someone in the factories or divisions to present an idea, something he's done, to the person who's the Best Practice Coordinator. And then we have a standard process of how to simply fill in the forms. When that's done, it's sent to the Community Head who has an overview of the community's competence and needs to decide if this is the best. If yes, he sends it out. And, we've constructed an IT-system that automatically sends it out to all the other members and suppliers in the system. And what the system demands from them is that they look at it, discuss it and get a decision from local management on whether to implement it or not. And they are then supposed to respond through the system...explain how it's done.... And they also have to answer in form of an implementation plan. [Erik, 011112:3]

\section{Enrolling more human and non-human elements in support of the program}

However, the BPT software application remained hidden away on the computers of the IT specialists in the project team, and thus did not convince many employees of the claims of the senior managers. To have any chance at all of becoming enrolled in support of the managers' program of action, the software needed to be made widely available and become integrated on many of the computers in the factories and divisions. This was in line with the senior managers' intention of developing an Intranet-based process throughout the company. The obvious choice could have been Lotus Notes, the platform most widely used throughout Engico. However, Engico had recently acquired a new IT platform, CoolSnake, from a US American IT-consulting firm, after senior managers had demanded a new product lifecycle management tool. The Engico IT-specialists described CoolSnake, as "leading edge" and one of the most advanced systems of its kind. Senior management intended it to replace the local 
IT-solutions at Engico thereby enabling a centralisation and homogenisation of the product data available at the company and a more efficient management of the life cycles of its many different products. Because of the support, which CoolSnake enjoyed at Engico among managers and IT specialists, this platform, and not Lotus Notes, became the obvious choice for BPT to run on.

However, while Lotus Notes facilitated all e-mail communication within the organisation as well as housed numerous databases with product data, manuals, project information and memos, CoolSnake was not yet widely known at the company. The senior managers believed that it was a good idea to install BPT as the first application on CoolSnake in order to demonstrate the platform's superior characteristics, in particular its ability to offer complete control over the workflow of documents, as one IT consultant explained:

CoolSnake is a PDM system which Engico uses... and, above all, will use in the future within product management. It's a Product Data Management system used to follow a product's life cycle from the planning stage until it is finished. And when it comes to BPT, it even makes use of a document structure... one can create documents and let them follow a certain life cycle or a certain workflow. And that's what BPT is all about...that you're able to follow a workflow...that the right persons can know when it is time for them to go through a document... or to create a specific document. [Stefan, 021022:1]

In other words, the senior managers attached CoolSnake's superior abilities to their program of action. However, CoolSnake, though embedded in Engico's IT infrastructure and described by BPT's proponents as the future backbone of their system, because of its abilities 
to control the flow of documents through the process, was an untested element and could thus not lend much support to the senior managers' program of action.

Nevertheless, the BPT team thought they had developed a fantastic system. - a prototype software modelled on a "best practice" case from a famous US American carmaker and a "state-of-the-art" IT platform. For its members the "idea of BPT as such" was so powerful, so positive and so strong, that they fully believed "soon, everybody will be using the BPT process, because it is so clearly the right thing to do" (Project leader 011112). However, although other elements had become attached to the program of action, others still did not support the claims made by the managers. The next step in the fact-building process was to "launch" the BPT process on the CoolSnake platform. After a number of successful tests on the company's test servers, the IT consultants gave the go-ahead for the BPT software to be installed on the mainframe server [4]. BPT became the first software application at Engico to run on CoolSnake. Anyone registered as a community member could now access the pilot community through the BPT homepage.

\section{The anti-programs}

In November 2000 the BPT process was launched in an unpretentious manner. Soon, it became apparent however that very few employees were using it. Senior managers put the blame solely on the prospective users:

Their [the intended users] current focus lies firmly with their own organisation...their own work with improvement. [...]. They have their networks where they meet once or twice a year and they have their meetings via telephone. And they are probably satisfied...they are successful in their area. But we do not get this [knowledge] from them in a structured way so that it can be shared with others...apart 
from the fact that two people in that group talk with each other...this informal interaction. [Karl, 020806:19]

Thus, the vast majority of Engico employees did not follow the program of action proposed by senior managers. Instead, they continued to use their local database solutions, their personal networks and their telephone meetings for sharing knowledge conducive to their work.

Employees who had tried out BPT explained the lack of interest in the BPT process by pointing to the system's impracticalities:

The system is constructed too rigidly. For example, there are so many passwords one has to remember in the process; and they have a limited lifespan. And because we don't work with BPT on a daily basis, we've had the problem that our passwords have expired... and it is very inconvenient to update them again. The system is unnecessarily convoluted. And there, I believe, one should have had more users involved from the beginning. [Hans, 020523:14]

Employees also mentioned that the improvements promised by the BPT team, such as cost reductions and increases in performance did not make sense to the engineers in the factories. Furthermore, the division managers found it difficult to place a value on the best practices submitted in order to measure performance improvements. As one divisional manager from Belgium pointed out:

How is this supposed to work? It's very difficult to say what the benefits will be. How can we measure things like improvements in the quality of work...worker satisfaction? [François, 030313] 
The BPT team was not only frustrated with the lack of commitment displayed by the intended users, they also managed to find a villain they could blame for their misfortunes: the CoolSnake Intranet platform. The BPT team, as well as the users in the factories, were dissatisfied with the overall performance of the platform. They were complaining about its quality and reliability, about the customer support they received from the platform's supplier, and about the system's complexity and rigidity:

We've had all too many problems with the intranet platform....and that's what currently creates the difficulties for us. And that's what the Community Heads out in the factories put the blame on...that's why they say they don't use the system. [Karl, 020806:7/8]

Soon after BPT's launch it had become apparent that not only CoolSnake, but also Engico's IT network, was not performing according to the BPT team' and senior managers' expectations. As one IT consultant explained:

The problems of course also have to do with the network infrastructure... what the network looks like around the world. In India, for example, the network infrastructure isn't that good. But still, the colleagues in India are expected to create something, which actually happens on a server here in Scandinavia. So, you have to accept that it's going to take them longer [to create and submit a best practice]. So, it's a question of performance....and it's also a question concerning CoolSnake, concerning the network and concerning the type of data that's prioritised when it comes to the traffic over the network. [Stefan, 021022:7] 
After struggling for a year to get the BPT process underway, to convince the process development managers out in the divisions to establish new communities, to obtain a commitment from managers who had already established communities, and to persuade the members of the existing communities to describe and submit their best practices through the system, all without success, the BPT team acknowledged in November 2001 that the initial launch of their process had been unsuccessful and removed the BPT application from the Production server - thereby making it less real.

\section{Countering the anti programs}

In order to get more employees to agree with their program of action, the proponents of BPT decided to increase information about the BPT system throughout Engico. They created an information pamphlet, a single, folded A4 page filled with information about the envisioned KMS, the BPT's homepage and the system's benefits (see Table 2), which was distributed in the organisation electronically and physically over the next few months. They also arranged for a series of training sessions to teach potential users about BPT's advantages and how they could become involved in the process.

\section{Reuse and spread of already proven improvements leading to:}

- A knowledge sharing culture

- Cost reduction at increased performance

- Faster continuous improvements process

- Support of learning processes

- Stimulated innovation level by reward system

Table 2: The arguments for introducing BPT Source: Extracted from the BPT information pamphlet (2001) 
However, the BPT team did not manage to counteract the anti-programs of the employees. The efforts at communicating the potential value of the BPT process to the users did not mean that the BPT became any more real. The information campaign and training sessions did not result in more employees agreeing with the senior managers' program-of-action to share more knowledge across organisational boundaries. The senior managers still had to rely on their employees' sense of moral obligation, and the employees were happy not to comply with their program of action. After all, they did still have Lotus Notes.

\section{Delegating the work to the object}

The BPT team' confidence in their system remained high though. They admitted that they had previously made a mistake when they had launched an untried technology and had not involved the users early on. From now on they would do things differently. This time they would ensure that the IT system worked smoothly before the BPT process was re-launched:

As far as I know very few people have actually used BPT, because of the performance of the system. So, we'll try and get that in order $[\ldots]$ and I have been involved in improving the workflow and so on...not only in CoolSnake, but also in the BPT software. This will make it easier for the user to use it. [Stefan, 021022:5]

Also, during a period of roughly one year, the BPT team were involved in simulations and test runs. According to the BPT project leader, this period was dominated by a "three-way battle" between Engico, its in-house IT consultants and the IT specialists from PLM Dynamics. On the one hand, the IT-consultants at PLM Dynamics worked on, and constantly released new CoolSnake versions and upgrades that were seen as solutions to the users' problems. The upgrades were tested on the Test server or the Greenhouse server. On the other hand, Engico's IT consultants had to continuously update the BPT software application in 
order to adapt it to the changing CoolSnake environment. And, finally, for the BPT team, the priority lay with keeping the prospective users interested in the BPT process while all this technical development work was going on.

In the end, the BPT team had to wait until January 2002 before the BPT application was finally installed on the Production server in the new CoolSnake version. However, even this new CoolSnake "Version 6.2" did not work flawlessly. Time-outs persisted and the system, instead of becoming less complex and easier to use, had become even more complicated and unstable through the changes that had been made. The BPT project leader explained:

[I]f I now want to make changes to the BPT software [...] I have to check all the other applications, which run on CoolSnake in the organisation in order to ensure that the changes I make, will not affect them. And why's that? Yes, because the CoolSnake system is so unstable. That's why one is forced to do that. The system's performance can be compromised for the most mysterious reasons. [Erik, 030128:6]

This quote alludes to the dilemma faced by developers as they attempt to load their programs of action with more and more statements in order to respond to the anti programs of their targeted groups. The software (BPT) and system (CoolSnake) that were once attached to their program of action in order to convince the users had brought with them more elements (e.g. the servers and other IT infrastructure at Engico) and were now so complicated and entangled that the BPT proponents had an increasingly difficult time making sense of it all. One IT consultant hints at this complexity when he explained:

Of course it [the problems] also have to do with the network... what the network looks like around the world. One can understand that in India, for example, the network infrastructure isn't that good. But 
still, employees in India are expected to create something, which actually happens on a server here in Scandinavia. So, there one has to accept that it's going to take them more time [to create and submit a best practice]. So, it's a question of performance....and it's also a question concerning CoolSnake, concerning the network and concerning the type of data that is prioritised when it comes to the traffic over the network. [Stefan, 021022:7]

But not only "remote" places such as India were affected. At a telephone conference involving the BPT project leader and a divisional manager (DM) from Belgium, the following conversation took place:

DM: It still takes such a long time to create a best practice, even without attaching a file. This is something that should've been different now with the new release [of CoolSnake]. Erik: Maybe, your network is too slow. I don't have those kinds of problems here... [...].

Erik: Let's try using the system, ok?

They take on different roles and try to create a "best practice".

Later, as DM is trying to create a "Response":

Erik: Oh, it's very slow...(pause)...I'm blocked...nothing...

Nothing happens for a couple of minutes.

Erik: The system is creating a best practice, but very slow.

Erik: (talks to me) Oh, this sounds very bad indeed.

DM: What can I do? Oh... It's very slow...

Erik: This mustn't have anything to do with the BPT system. We're still working in the Test server environment. Maybe, a lot of people 
are using that server at the moment?

DM has to leave the room and take a phone call.

Erik: (talks to me) This is bad. Their network is probably slow...I

didn't have any problems creating the best practice, even with a file

attached. If it takes too long, the people won't accept the

system...they won't work with it. [Notes from a telephone

conference, 020906]

Furthermore, the technicist approach employed here, means that all focus rests with the object that the work has been delegated to (the BPT software + CoolSnake platform), and no more focus is given to the other elements that still need to be in place: the information about the program of action ("please, share more knowledge across organisational boundaries"), the oral support of the management, etc.

The CoolSnake system's inner workings and functions did not become black-boxed through the changes made by the experts from PLM Dynamics and Engico's IT consultants. The platform did not become a taken-for-granted part of Engico's IT infrastructure - hidden, because of its flawless workings, under layers of software applications. Instead it remained wide open and the object of continuous negotiations and mediations.

The BPT team struggled for nearly three years to get their process underway. They attempted to convince the process development managers out in the divisions to establish new communities, to obtain a commitment from managers, who had already established communities, to solve the technical difficulties, and to persuade the members of the existing communities to describe and submit their best practices through the system. They did not succeed, and towards the end of 2003 acknowledged that the BPT project was a failure. 


\section{DISCUSSION: Towards a new approach for understanding the development and introduction of a KMS}

The study shows that the BPT project, would be difficult to explain within the physicalist “diffusion model” (see Latour, 1986; 1987; Czarniawska, 2002) and the logic of “implementation", traditionally used to explain the development and introduction of KMS in organisations. It shows that these processes are seldom actualised in a neat and linear movement from some source of origin to its site of implementation, but tend to be far messier, serendipitous and contingent than the implementation logic assumes. The process traced in this study resembles what has in anthropology and other fields been referred to as “appropriation", the simultaneous construction and consumption of novel technologies. The term appropriation signifies the assignment of agency to people towards whom a novel technology or other program of action is directed. While according to the implementation logic, people are mere puppets in the hands of the new technology, appropriation alludes to the idea that people take in novel technologies and programs of action in general and make them there own - or not. In this respect, a translation perspective on KMS encourages a key question: how does a novel program of action become appropriated by employees in an organisation as a routinely used KMS? The case of the BPT process offers an excellent example to explore this question, as the procedure at the time of study was under development at Engico and not yet real.

From ANT we learn that projects fail, because some participants do not manage to translate the interests of other participants and therefore fail to align them (Latour, 1987). The translation approach to organisation studies corroborates this insight, but adds that actions are sometimes not translatable into one another, or the connection points are not maintained with enough care (see e.g. Czarniawska, 2009). We could see this clearly in our case that the 
management attempted to translate their program of action "please, share more knowledge across organisational boundaries" from idea into practice by seeking the support from another untried innovation - the CoolSnake platform. From Latour's (1996) narrative on Aramis we learn that translating one innovation with the support of another one is a precarious enterprise.

Also, the BPT team did not consider the existing activities and processes of knowledge sharing unfolding in the factories and divisions and connected and stabilised by a routinely used and therefore taken-for-granted technology - the Lotus Notes software application, which never became questioned by the BPT, and in fact kept the latter from becoming a reality. Thus, the BPT case corroborates Latour's (1987) “Janus face" argument, that technologies cannot convince anyone before they work. Instead, people become convinced once the technology works. And, to work, novel technologies need to accumulate reality via reports, models, meetings and other activities, routines, objects, exhibits, etc. Thus, contra to the rational implementation logic, reality here is the product of continuous and often irrational socio-material processes of translation and appropriation. These processes are not progressive, but iterative. "A technological project is neither realistic nor unrealistic; it takes on reality, or loses it, by degrees" (Latour, 1996: 85).

In order for a KM project to succeed and the KMS to become a stable, taken for granted part of the daily work activities in an organisation, the actions of human and non-human others, apart from the project group members, are needed, and it is indeterminable from the beginning and throughout the process what these actions will be. As our case has shown these actions can be many things and they are unpredictable. They involve people (e.g. from early supporters to detractors of the BPT system), machines (e.g. IT platforms in diverse countries viewed as being friendly, neutral or constraining towards the BPT), objects (e.g. CoolSnake 
software translated into an 'evil' category at the end of the launch phase), and other actors (e.g. PLM Dynamics updating the CoolSnake platform whenever they found most convenient for PLM). And they all played a part in translating and transforming the original program of action.

In the case reported here, however, the BPT never became real enough through these processes of translation. It was more properly an object of conversation than something that the engineers at Engico could use in their daily work to share knowledge in the form of best practices with their colleagues in other factories and learn from one another. In fact, it did not even become a object of conversation in many parts of Engico. In true technicist fashion, test prototypes of BPT were built, and individual technologies were demonstrated and tested, but the relevant actors at Engico did not bother anymore to support the work by instructing people on what BPT was intended to be in the first place. The work of making the KMS a reality was delegated onto the object (the BPT system) itself.

Thus, our study shows that it does not suffice to state that the design of the new business process tool is "user centered". Users are only a part of the story of successful design and innovation. And, as we have learned from Latour (1987), it is not enough to design the new device or its practices of use. It is necessary to convince users to use the new technology.

Using a translation approach, the analysis of KMS appropriation demonstrates that, in practice, the program of action of the managers got increasingly complicated as they responded to the anti programs of the employees. The richness and intricacy of translating and connecting diverse actions, and of maintaining and stabilising these connections as conditions change, strongly contrasts with the linear simplicity of models for KMS "implementation" proposed by the traditional managerial literature in the field (see e.g. 
Borghoff and Pareschi, 2013; Wiig, 2012). The authors believe that developing knowledge management practice in organisations will benefit from recognition of the far-reaching diversity of intended and unintended actions and objects and their critical role in translating KM ideas into practice. Organising the management of knowledge in practice subsequently demands less focus on building the "perfect system" and more awareness among involved actors of how the tools they introduce - the products of social and material practice - are contingent and local, rather than conclusive and universal.

Drawing from the insights gained from the Engico case using an ANT perspective, it is possible to sketch a conceptual framework that helps to further understand the development and introduction of KMS as a set of appropriation processes. The framework is multilayered and includes associations between humans, between non-humans and between human and non-human elements that continuously shape and transform one another through programs and anti-programs of action. These elements are arranged along an onion-like structure, one embedded within the other (See Figure 1). Rather than homogeneous and with clear roles, the model's elements are dynamic and heterogeneous. They usually change their roles and expectations overtime; as well as their relationships with other elements (from congruent to contested and vice-versa), all shaped by other elements' actions that might had happen at a different time and in a different space. Simultaneously, as the elements' actions are situated, and influenced by a combination of organisational, personal, and contextual random events, their associations cannot be planned to achieve specific goals. 


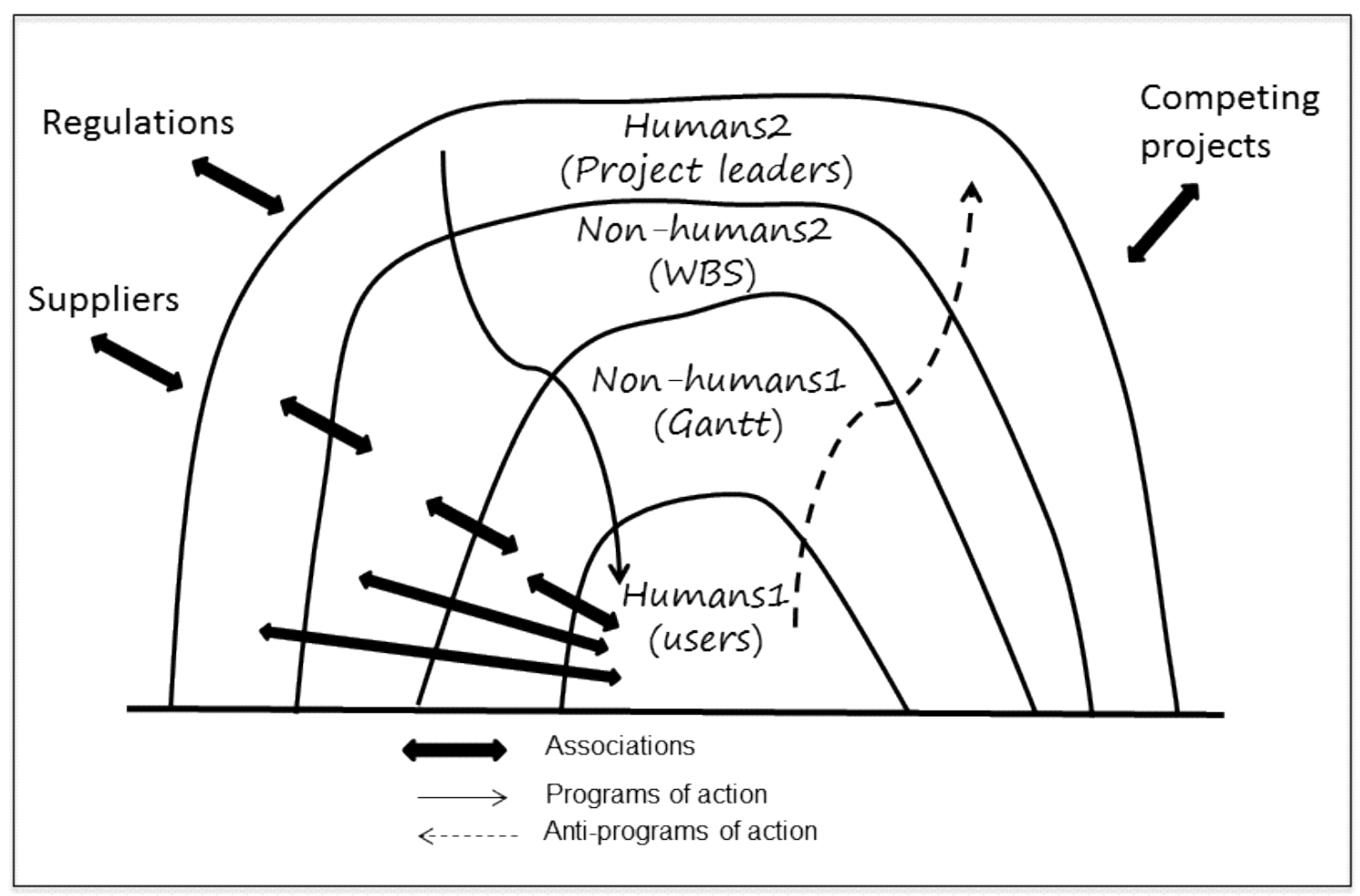

Figure 1: Constructing Projects

Users constitute a key human element of the framework, not in themselves, but because they are the ones targeted by the BPT developers. They are the ones that the managers direct their program of action ('Please share your knowledge') towards. Users, nevertheless, are usually heterogeneous, like in the Engico case. Users from diverse factories located in different countries had differentiated needs priorities and expectations, resulting in varying degrees of support for, or resistance to the BPT application.

The BPT software, a non-human element becomes attached to the program of action in order to garner support from the users. Not only its (technical) role may be amended (e.g. software updates are needed to adapt its application to changing inputs and processes), but it is also interpreted and treated differently within the network of people and other non-human elements in which it operates. 
At Engico for example, the BPT software was positioned as the main interface end-users should use to share their knowledge across organisational boundaries. The BPT software however could not run by itself. It needed to be connected to an IT platform on which it could run. It was not static, but was constantly produced while it was consumed by the users. Not only it passed through a series of phases during its development, but also different actors perceived it differently at different stages and sites. To the BPT development team it was a great idea. Its creators continuously supported the BPT software. To them this technology represented a key innovation to assist transferring best practices at Engico. It also represented their careers, reputations and dreams. This helps to explain the positive interpretations they provided to the BPT software versions and the negative interpretations attributed to other non-human components — such as the one-time villain CoolSnake system.

The CoolSnake IT platform was another non-human object that needed to harmoniously interact with other technologies (BPT software). Like any other technology, the IT-based platform changed overtime. CoolSnake needed continuous software updates that in turn affected how BPT application ran. Further, generic technologies also needed to be adapted to the local conditions of operation. Technologies however, are developed, maintained supported or undermined by people. In the Engico case, the IT specialists from PLM Dynamics, with their own interests, supported the BPT team in such a way to meet customer requirements (that were somehow unclear and open) as well as their own commercial and personal goals. This means, the extent to which CoolSnake met Engico's requirements was not only a technical matter, but also a social affair, as "PLM Dynamics consultants updated the platform whenever they found most convenient for PLM”. It follows that machinemachine integration is constrained by social issues surrounding the people-machine network. 
In this component of the framework, competing technologies are also considered as they affect the extent to which upcoming technologies are stabilised. While the CoolSnake platform was selected because it was seen as leading edge technology; users considered it unstable (too many new versions/updates) and not very friendly (need to change passwords over short periods). Conversely, the 'old fashioned' Lotus Notes software was seen as reliable and user friendly as it was a stable technology at Engico.

The development teams include all teams that promoted — in greater or lesser extent—in the development and introduction of the KMS. In this case, this element includes the BPT team as well as the PLM Dynamics team. The BPT team played a key role, as its members were enticed by senior managers to build the BPT. However, the team was highly dependent on the actions of other humans and non-humans. The BPT team attached the BPT software and the CoolSnake platform to the managers' program of action in the hope of strengthening their claims and making their envisioned KMS a routinely used "real" piece of equipment at Engico.

The BPT team however, was not only responsible for its development and introduction. They also had to argue and negotiate with other actors (PLM Dynamics team; Engico divisional managers and other users) and convince them, expecting them to undertake the desired actions. This means their actions directly affected PLM Dynamics team participation, BPT development of updates and end-users participation. The development team however, responded to Division managers who provided acceptance and resources for the BPT project. As such, those managers affected — to some extent — the span of life of the BPT project. It follows that rather than interpreting their role as 'driving' the introduction process, they can be best regarded as attempting to build associations between humans and non-humans to support BPT appropriation across Engico. 
All those elements are drawn together or not through associations (see double arrows in Figure 1) with different features, roles and dynamics. Some associations are between humans and other humans. This is a very common form of linkage as it involves all coordinating, negotiating and influencing activities developed by one group to influence another group. This process is interactive and non-linear since the receiving group might react in positive, negative or indifferent ways to the requests of the other group. In turns, this might generate a re-action of the first group. At Engico, the BPT team attempted (but ultimately failed) to buy the support of end-users for their system through information campaigns and training sessions.

Other associations may emerge between humans and non-humans. The authors define this association as the socially constructed interpretation of the connections between humans and non-humans. For example, humans can interpret machines as 'evil' or 'friendly' depending on the role of the machine in relation to the current goals/priorities and agendas of human actors, who are embedded into a network of other human actors, machines and objects. Simultaneously, machines can be said to have agency as they can function in a different way than expected. This might cause human actors' reactions that can result in a range of outcomes for the human-machine social interaction.

Additional associations may emerge in-between non-humans. These associations refer to the character of the relationships between non-humans. Associations between non-humans can be anything from friendly and easy to unfriendly and difficult. Because of technological and socially constructed reasons, some objects can be more or less 'compatible' with other objects. On the one hand, intrinsic features of a technology (e.g. technological base; computer language) may affect the extent to which one technology can become attached to another technology. On the other hand, technologies are embedded in networks of pluralistic people 
and diverse objects. This implies the extent a particular machine can function as expected depends on actions/reactions of other humans and non-humans, who have diverse goals/priorities/agendas.

At Engico, the CoolSnake system remained wide open and its performance was continuously negotiated between the PLM Dynamics IT specialists, Engico's IT consultants and the BPT team, something that affected the new BPT software and specially, the intended users of the BPT system. When the end-users' support was indifferent - as they already had their limited but stabilised communities of practice (i.e. a particular association between humans) and database systems, the BPT team chose not to continue to maintain this element previously attached to their program, but to instead delegate all of the work to the object (the BPT software + CoolSnake platform). This, according to Latour (1990) is detrimental when attempting to enrol and discipline human actors, such as customers or users, as it is only the accumulation of all the elements that have been attached that gives the impression that some reality has been achieved during the KMS appropriation.

The dynamics of the framework can be observed when systems developers enacted programs of action to convince end-users to use the new BPT tool and, end-users enacted antiprograms of actions to not to use the BPT. Both programs and anti-programs of actions cross diverse human and non-human elements through the deliberate building of associations between humans and non-humans, humans and humans, and non-humans and non-humans.

The proposed framework helps to understand the inextricable ways in which pluralistic people and diverse objects construct their technical and social relations through multiple associations that produce sets of intended and unintended consequences and in some cases a stabilised network (i.e. a routinely used KMS in an organisation). This framework therefore 
must be seen as a road map to understand the dynamics of KMS appropriation as an iterative process of production and consumption of the system. Thus, if the designers of a novel KMS stick to technical fixes and focus only on their object (i.e. an IT-based system), while failing at its embeddedness and the contributing relationships within the broader environment, at choosing the test sites, at generating its acceptance within the organisational decision-making structure, at adjusting its demands to its social, financial, material or other environment, and so on, they will hardly get to a routinely used piece of equipment. As Tsoukas (1996, p. 21) pointed out, the carriers of knowledge are a firm's practices and routines. The carriers are not the systems and tools designed to distribute explicit descriptions about this knowledge throughout the organisation.

\section{Conclusion: From KMS implementation to KMS appropriation}

This study drew on ANT to illuminate the complexities involved when constructing an ITbased KMS in a large multinational organisation. While conventional models of KMS implementation focused on a rational definition and the planning of the stages to control time, people and material resources, a translation perspective approach is a complex, multilayered and messy process drawing together managers, employees, software programs, IT platforms, and other objects. During translation, the associations among them change, but importantly they also play dynamic roles. The authors called this whole process, KMS appropriation.

The paper shows how the managers' program of action - "please share your knowledge across organisational boundaries" - is translated into the BPT project aimed at enticing the human actors to follow that program of action. This can be seen as a set of ill-aligned efforts, undertaken by its proponents, to make the BPT, a taken-for-granted part of heterogeneous participants (people, machines, software, and reports) aiming at translating ideas (engineering best-practices) into text (software programs). Then, this software programme needed to be 
made compatible with a particular IT-platform, something that encompasses negotiation and the use of power games between different factories and divisions. Finally, the end-users needed to be convinced to use the BPT. All this process involves multiple actors negotiating and agreeing on what constitutes engineering best practice and how to capture and distribute best-practices, and defining the suitable software language and computer platforms to be used. However, it also involves dealing with uncertainty brought about by the situational nature of the practices performed, the unexpected events emerging from third parties, and the unknown response of the end-users to the final product. The latter involves translating people's and objects' (e.g. computer programs' or IT hardware) identities, roles, and dreams into new identities, roles, and dreams.

The authors posit that the translation approach opens opportunities for overcoming some of the weaknesses of the conventional "implementation" approaches described by Dufour and Steane (2007). For example, by considering the non-rational actions of diverse organisational actors and the fluid conceptions of stages, the classical approach would be able to overcome determinism. By considering human and non-human (machines, tools, software, organisational rules, etc.) symmetrically, as well as the role of serendipitous events, the behavioural and political approaches would be able to maintain their main strength - the use of a social constructivist view of organising and human actions - and overcome some of their key weaknesses (namely, the deterministic view of human nature within the behavioural approach, and the under-estimation of the rational and collaborative processes within the political approach). Similarly, by highlighting how agency is embedded in networks of human and non-human elements, some of the weaknesses of the contingency approach can be overcome, such as the over-reliance on contextual forces to explain organisational outcomes. 
A key limitation of this study is that it is based on a case study from which it is not possible to generalise (Yin, 2013). On the other hand, the rich information, provided from the empirical evidence, is also a strength upon which the authors have capitalised. Drawing on the insights, which emerged from the empirical evidence and inspired by ANT, a conceptual framework was developed. This framework outlines the complex interrelations emerging as part of the network building processes through the associations between humans and nonhumans; it also helps students of KMS to understand the dynamics of the social processes that underpin the technical processes.

The proposed framework brings a number of implications for practice. By making practitioners aware of the diverse roles human and non-human elements can play, as well as their associations, practitioners will be better positioned to deal with paradoxes, unexpected outcomes, and the competing needs that are likely to emerge during the appropriation of KMS. After all, a hundred different employees will follow a hundred different paths after being confronted with a novel program of action, such as "please share more knowledge across organisational boundaries". For example, by delaying user involvement in the implementation process, the BPT team unintentionally alienated end-users at several manufacturing sites, making it difficult for them to be committed to the BPT project at the launch stage. Simultaneously, the lack of commitment of the end-users can be also credited to the use of a new and untried technology. Moreover, this CoolSnake platform was little known, and nobody knew, in advance, how it would work together with the BPT software. In turn, it was selected because of its 'leading edge' innovative technical features, combined with a significant amount of faith (from the BPT team and Engico's IT consultants) that 'it will work'. 
This framework also helps practitioners to make explicit their taken-for-granted assumptions about pluralistic people (from diverse manufacturing sites), machines (developed in different time and space by teams with particular intentions), and the associations among them. That is, it assists practitioners to uncover emerging conflicting issues between human and machines (e.g. will the users accept the new system?); among machines (e.g. will one piece of technology (BPT software) be compatible enough with another (e.g. CoolSnake platform)?); and among humans. Moreover, the framework helps practitioners to recognise the different identities humans and non-humans take, overtime, as a result of emerging associations. For example, at a later point in time, the BPT proponents in the case study understood CoolSnake as a more complicated and unstable platform than they realised earlier on in the process. At another stage the users saw Lotus Notes as a competitor of CoolSnake. Additionally, CoolSnake changed identities at different stages of the BPT, for example, from 'leading edge' technology (at the beginning of the project) to culprit resulting from the lack of end-user acceptance of the BPT program (at the end of the BPT program).

Finally, by recognising the diverse roles and assumptions attached to human and non-human elements, as well as their associations, practitioners will be able to define specific battlelines to deal with the series of translations (of identities, roles, and interpretations), involving human and non-human elements and their associations, through the appropriation process.

Those research findings open important avenues to further investigate, from alternative perspectives, the KMS development and introduction. The empirical validation of the proposed framework is a first candidate for future research. Such research would assist in improving knowledge about the socio-material associations, shaping what the authors have called the appropriation of KMS, and refining the proposed framework. 
The second candidate for research is the use of the proposed framework, complemented by practice-based lenses (Nicolini, Gherardi and Yanov, 2003; Gherardi, 2009; Nicolini, 2013), especially as both constructs share similar epistemological bases. Practice lenses can be useful to focus research on how people, machines, and their linkages, perform together and evolve since most practice models focus on the constitutive elements of the proposed framework, namely: actions, actors, contexts, situations, relationships, identities, interpretation, and embeddedness. Further, like ANT, the practice-based approach is a nondeterminist view that considers social actions as building social order processes, which account for the complexity of human interaction (Guzman, 2013).

Finally, as hinted by Dufour and Steane (2007), the concept of organising would also assist in making sense of how the simultaneous interaction of ideas, contexts, processes, and associations result in a constellation of practices. Organising, according to Czarniawska (2008), refers to how multiple actors, including people, objects, machine and rules, interact, and how they construct meaningful narratives to justify their actions. Hence, it is during organising that people, objects, rules, and third parties have their identities (roles, resources, goals, meaning, and relevance) translated. To know how diverse actors do what they do, including their intended and real goals, it is necessary to focus on the practices of organising. Therefore, by focusing on practices of organising, new insights can be gained as to how diverse human and non-human actors are translated and this, in turn, provides a more realistic idea of the overall organising of KMS appropriation. 


\section{References}

Adams, G. L., and Lamont, B. T. (2003), "Knowledge management systems and developing sustainable competitive advantage", Journal of Knowledge Management, Vol. 7 No. 2 , pp.142-154.

Akhavan, P., Jafari, M., and Fathian, M. (2006), "Critical success factors of knowledge management systems: a multicase analysis", Europen Business Review, Vol. 18 No. 2, pp. 97-113.

Bhatt, G. D. (2001), "Knowledge management in organizations: examining the interaction between technologies, techniques, and people", Journal of Knowledge Management, Vol. 5 No. 1, pp. 68-75.

Bijker, W.E., Hughes, T. and Pinch, T. (1990), The social construction of technological systems, The MIT Press, Cambridge, Massachusetts.

Bleakley, A. (2012), "The proof is in the pudding: Putting actor-network-theory to work in medical education", Medical teacher, Vol. 34 No. 6, pp. 462-467.

Borghoff, U. M. and Pareshi, R. (2013), Information technology for knowledge management, Springer Science \& Business Media, Berlin.

Callon, M. (1986), "Some Elements of Sociology of Translation: Domestication of the Scallops and the Fishermen of the Saint Brieuc Bay", In John Law (ed.), Power, Action, and Belief: A new sociology of Knowledge?, Barnes \& Noble Inc., South Orange, NJ, pp. 196-223.

Callon, M., and Law, J. (1982), "On interests and their transformation: enrolment and counter-enrolment", Social studies of science, Vol. 12, No. 4, pp. 615-625.

Carneiro, A. (2000), "How does knowledge management influence innovation and competitiveness? ", Journal of Knowledge Management, Vol. 4 No. 2, pp. 87-98.

Cordeiro-Nilsson, C. and Hawamdeh, S. (2011), "Leveraging socio-culturally situated tacit knowledge", Journal of Knowledge Management, Vol. 15 No. 1, pp. 88-103. 
Czarniawska, B. (2014), Social Science Research: From Field to Desk, SAGE, London.

Czarniawska, B. (2009), "Commentary: STS meets MOS", Organization, Vol. 16 No. 1, pp. 155-160.

Czarniawska, B. (2008), "Organizing: how to study it and how to write about it", Qualitative Research in Organizations and Management: An International Journal, Vol. 3 No. 1, pp. 4-20.

Czarniawska, B., and Hernes, T. (2005), Actor-network theory and organizing, Copenhagen Business School Press, Copenhagen.

Czarniawska, B., and Sevón, G. (Eds.), (2005), Global ideas: how ideas, objects and practices travel in a global economy (Vol. 13), Copenhagen Business School Press, Copenhagen.

Czarniawska, B. (1997), Narrating the organization: Dramas of institutional identity, University of Chicago Press, Chicago.

Czarniawska, B., and Sevón, G. (Eds.), (1996), Translating organizational change (Vol. 56), Walter de Gruyter, Berlin.

Davenport, T. H., and Prusak, L. (1998), Working knowledge: How organizations manage what they know, Harvard Business Press, Cambridge, MA.

Diedrich, A. (2004), Engineering knowledge. How engineers and managers practice knowledge management, BAS Publishing, Göteborg.

Du Plessis, M. (2007), "Knowledge Management: What makes complex implementations successful? ", Journal of Knowledge Management, Vol. 11 No. 2, pp. 91-101.

Dufour, Y. and Steane, P. (2007), "Implementing knowledge management: a more robust model", Journal of Knowledge Management, Vol. 11 No. 6, pp. 68-80.

Fenwick, T. and Edwards, R. (2010), Actor-network theory in education, Routledge, London. Gallupe, B. (2001), "Knowledge management systems: surveying the landscape", International Journal of Management Reviews, Vol. 3 No. 1, pp. 61-77. 
Graham, I. D., Logan, J., Harrison, M. B., Straus, S. E., Tetroe, J., Caswell, W., and Robinson, N. (2006), "Lost in knowledge translation: time for a map? ", Journal of continuing education in the health professions, Vol. 26 No. 1, pp. 13-24.

Goh, S. (2002), "Managing effective knowledge transfer: an integrative framework and some practice implications", Journal of Knowledge Management, Vol. 6 No. 1, pp. 23-30.

Guzman, G. (2013), "The grey textures of practice and knowledge: review and framework", European Business Review, Vol. 25 No. 5, pp.429-452.

Halawi, L.A., McCarthy, R.V., and Aronson, J.E. (2006), "Knowledge management and the competitive strategy of the firm", The Learning Organization, Vol. 13 No. 4, pp. 384397.

Hansen, M.T. (2002), "Knowledge Networks: Explaining Effective Knowledge Sharing in Multiunit Companies", Organization Science, Vol. 13 No. 3, pp. 232-248.

Iverson, J. O., and McPhee, R. D. (2002), "Knowledge management in communities of practice", Management Communication Quarterly, Vol. 16 No. 2, PP. 259.

Kjaergaard, A., and Kautz, K. (2006), "A process model of establishing knowledge management: Insights from a longitudinal field study", Omega, Vol. 36 No. 2, pp. 282297.

Kogut, B., and Zander, U. (1992), "Knowledge of the firm, combinative capabilities, and the replication of technology", Organization Science, Vol. 3 No. 3, pp. 383-397.

Kumar, A.J., and Ganesh, L.S. (2009), "Research on knowledge transfer in organizations: a morphology", Journal of Knowledge Management, Vol. 13 No. 4, pp. 161-174.

Latour, B. (2005), Reassembling the social-an introduction to actor-network-theory, Oxford University Press, Oxford.

Latour, B. (1999), Pandora's hope: essays on the reality of science studies, Harvard University Press, Cambridge, MA. 
Latour, B. (1996), Aramis, or, the love of technology, Harvard University Press, Cambridge, MA.

Latour, B. (1990), "Technology is society made durable", The Sociological Review, Vol. 38, No. 1, pp. 103-131.

Latour, B. (1987), Science in action: How to follow scientists and engineers through society, Harvard university press, Cambridge, MA.

Latour, B. (1986), "The powers of association", Sociological Review Monograph, Vol. 32 No. S1, pp. 264-280.

Latour, B., and Woolgar, S. (1979), Laboratory life: The social construction of scientific facts, Sage, Beverly Hills.

Law, J. (1992), "Notes on the theory of the actor-network: Ordering, strategy, and heterogeneity", Systems Practice, Vol. 5 No. 4, pp. 379-393.

Lech, P. (2014), "Managing knowledge in IT projects: a framework for enterprise system implementation", Journal of Knowledge Management, Vol. 18, No. 3, pp. 551-573.

Maier, R., and Remus, U. (2002), "Defining process-oriented knowledge management strategies", Knowledge and Process Management, Vol. 9 No. 2, pp. 103-118.

March, J. G., Schulz, M., and Zhou, X. (2000), The dynamics of rules: Change in written organizational codes, Stanford University Press, Stanford, CA.

Matayong, S. and Mahmood, A.K. (2013), "The review of approaches to knowledge management systems studies", Journal of Knowledge Management, Vol. 17 No. 3, pp. 472-490.

Newell, S. (2015), "Managing knowledge and managing knowledge work: what we know and what the future holds", Journal of Information Technology, Vol. 30 No. 1, pp. 1-17.

Ofek, E., and Sarvary, M. (2001), "Leveraging the customer base: creating competitive advantage through knowledge management", Management Science, Vol. 47 No. 11, pp. 1441-1456. 
Orlikowski, W. J. (2002), "Knowing in practice: Enacting a collective capability in distributed organizing", Organization science, Vol. 13, No. 3, pp. 249-273.

Politis, J.D. (2003), "The connection between trust and knowledge management : what are its implications for team performance", Journal of Knowledge Management, Vol. 7 No. 5, pp. 55-66.

Rao, M. (2005), Knowledge Management Tools and Techniques: Practitioners and Experts Evaluate KM Solutions, Elsevier Butterworth-Heinemann, MA, USA.

Ruggles, R. (1998), "The state of the notion: Knowledge management in practice", California Management Review, Vol. 40 No. 3, pp. 80-89.

Spyridonidis, D., Currie, G., Heusinkveld, S., Strauss, K., and Sturdy, A. (2014), "New Developments in Translation Research", International Journal of Management Reviews, Vol. 16 No. 2, pp. 245-248.

Styhre, A. (2003), "Knowledge management beyond codification: knowing as practice/concept", Journal of Knowledge Management, Vol. 7 No. 5, pp. 32-40.

Su, N. M., Wilensky, H. N., and Redmiles, D. F. (2012), "Doing business with theory: Communities of practice in knowledge management", Computer Supported Cooperative Work (CSCW), Vol. 21 No. 2-3, pp. 111-162.

Sua, K., Hwang, S., and Liuc, T. (2000), "Knowledge architecture and framework design for preventing human error in maintenance tasks", Expert Systems with Applications, Vol. 19 No. 3, pp. 219-228.

Subramaniam, M., and Youndt, M.A. (2005), "The influence of intellectual capital on the types of innovative capabilities", Academy of Management Journal, Vol. 48 No. 3, pp. $450-463$.

Szulanski, G. (2002), Sticky knowledge: Barriers to knowing in the firm, Sage, London. von Krogh, G., Nonaka, I. , and Aben, M. (2001), "Making the most of your company's knowledge: a strategic framework", Long Range Planning, Vol. 34 No. 4 , pp. 421-439. 
Tsoukas, H. (2011), "How should we understand tacit knowledge? A phenomenological view", in Easterby-Smith, M. and Lyles, M. (Eds.) Handbook of organizational learning \& knowledge management, Wiley, Chichester, pp. 453-476.

Tsoukas, H. and Vladimirou, E. (2001), "What is organizational knowledge?", Journal of Management Studies, Vol. 38, No. 7, pp. 973-93

Walsh, J. P., and Ungson, G. R. (1991), "Organizational memory", Academy of Management Review, Vol. 16 No. 1, pp. 57-91.

Wiig, K. (2012), People-focused knowledge management, Routledge, London.

Wong, K.Y. (2005), "Critical success factors for implementing knowledge management in small and medium enterprises", Industrial Management \& Data Systems, Vol. 105, No. 3, pp. 261-279.

Yin, R. K. (2013), Case study research: Design and methods, Sage, London.

Zheng, W., Yang, B., and McLean, G.N. (2010), "Linking organizational culture, structure, strategy, and organizational effectiveness: Mediating role of knowledge management", Journal of Business Research, Vol. 63 No. 7 , pp. 763-771.

Zollo, M., and Winter, S. G. (2002), "Deliberate learning and the evolution of dynamic capabilities", Organization science, Vol. 13 No. 3, pp. 339-351.

Notes

[1] There are, of course, exceptions. See for example Bhatt (2001).

[2] The name of the company and all our interlocutors have been changed to preserve their anonymity.

[3] We would like to stress however, following Latour (1987), that we do not see the distinctions between the phases as immediately given. We use them here in order to provide 
the reader with a brief, abstract overview of the complex interactions, which we followed for a longer period, realising at the same time that in reality the project did not lie along a clearcut trajectory going through different phases.

[4] Engico had three servers: the Development server, the Greenhouse server and the Production server. The Development server was the one on which new software applications were developed. It was not very powerful and frequently broke down when applications were tested. Once the applications were developed and worked promisingly, they were installed on the Greenhouse server, which mirrored the IT environment at the company. Software applications such as BPT were run and tested on the Greenhouse server in order to determine if they worked flawlessly. Only when the software worked on the Greenhouse server was it given the go-ahead to be 'launched' throughout the organization on the mainframe production server facilitating all of the company's daily IT communication. 